\title{
Workplace Stresses and Musculoskeletal Disorders Among Nurses: A Cross-Sectional Study
}

\author{
Alireza Dehdashti, ${ }^{1, *}$ Semira Mehralizadeh, ${ }^{2}$ and Zahra Mahjoubi ${ }^{3}$ \\ ${ }^{1}$ Social Determinants of Health Research Center, Semnan University of Medical Sciences, Semnan, Iran \\ ${ }^{2}$ Faculty of Medicine, Iran University of Medical Sciences, Tehran, Iran \\ ${ }^{3}$ Faculty of Health, Semnan University of Medical Sciences, Semnan, Iran \\ "Corresponding author: Alireza Dehdashti, Social Determinants of Health Research Center, Semnan University of Medical sciences, Semnan, Iran. Tel: +98-9122113783, E-mail: \\ dehdashti@semums.ac.ir
}

Received 2017 January 14; Revised 2017 March 05; Accepted 2017 March 23.

\begin{abstract}
Objectives: Work-related musculoskeletal disorders are a significant occupational problem among employees and workers. This study attempted to explore the effect of stressors in the hospital environment on nurses' development of musculoskeletal disorders. Methods: We conducted a cross-sectional survey in a random sample of 123 hospital nurses from Semnan University of Medical Sciences. Data were collected during working days over 3 months starting from January 2014. Participants completed a standardized questionnaire for stresses and musculoskeletal disorders at work. Musculoskeletal disorders were used as the dependent variables, while demographic, physical, and psychosocial work factors were used as independent variables.

Results: Our study revealed prevalence of low back ache, neck ache, shoulder ache, arm-elbow ache, and hand-wrist pain rated $48.3 \%, 39.5 \%, 33.1 \%, 31.3 \%$, and $23.4 \%$, respectively. The findings showed significant statistical association between musculoskeletal complaints in neck and upper extremity with exposed stress levels $(\mathrm{P}=0.04)$. Musculoskeletal symptoms rates increased in employees experienced poor work posture $(\mathrm{P}=0.01)$, fatigue $(\mathrm{P}=0.04)$, and work-family conflict $(\mathrm{P}=0.04)$.

Conclusions: This study provides indication of the relationship between work environment stress levels and musculoskeletal disorders. Physical and psychosocial stressors should be considered for the development of preventive measures.
\end{abstract}

Keywords: Workloads, Risk Assessment, Musculoskeletal Injuries

\section{Background}

Exposure to occupational stressors may affect soft tissues resulting in musculoskeletal pains with nontraumatic origin (1). Musculoskeletal disorders research, grounded in work environment contexts, has been firmly established as an area of research in recent years $(2,3)$. Musculoskeletal complaints indicate a common occupational health problem and significant threat to nurses' health. Neck problems (46\%), shoulder problems (35\%), and back problems (47\%) have been experienced by nurses working for at least 1 year (4). A study among Iranian health care workers has reported lower back pain as the most prevalent symptoms (5). A combination of physical and psychosocial stressors increases the risk of musculoskeletal disorders (6).

Previous research consistently documented that working conditions and nature as well as the intensity of job stressors will likely lead to musculoskeletal injuries (7-9). Previous epidemiological studies have shown numerous risk factors for musculoskeletal disorders in various occupational settings including individual characteristics, awkward work posture, manual handling of heavy loads, repetitive movements, forceful exertion, job stress, work scheduling, and long working hours (10-15).

Nurses are exposed to a wide range of occupational stressors that may adversely affect on their health. Previous research in a large hospital applying a questionnaire includes both task level and social and organizational factors and reported a significant association between psychosocial factors and self reported musculoskeletal symptoms at various body sites among Iranian nurses (16).

Evidence suggests that there may be multiple causes for musculoskeletal disorders, exposure to a specific risk factor does not necessarily result in the development of a musculoskeletal symptom, and the full range of factors must be analyzed to understand and establish the cause the disorders $(17,18)$. Far fewer studies have been performed to describe the possible mechanisms for linking the role of factors in the development of musculoskeletal disorders. The analyses of the associations between occupational stressors and work related musculoskeletal injury outcomes may help to recognize the components and propose corrected actions and prevention programs. The present research based on a conceptual framework of risk factors including work posture, role related stressors, psychological workloads, fatigue, and musculoskeletal com- 
pliant as outcome.

The purpose of the present cross-sectional research was to determine the prevalence and evaluate the associations of various work environment stressors with musculoskeletal disorders in a sample of Iranian university hospital nurses in Semnan. This study attempted to contribute to the knowledge base by exploring the influence of work behavior and occupational risk factors on the development musculoskeletal complaints as perceived by the nurse.

\section{Methods}

This study was a cross-sectional design based on a questionnaire survey. The study was conducted from January 2014 and continued for 3 months. The study subjects were nurses randomly selected from the Velayat hospital affiliated to Semnan University of Medical Sciences located in Damghan. The survey applied a self-reported questionnaire to collect required data. The study was conducted from January 2014 and continued for 3 months. Out of around 400 nurses employing in the university hospital, 123 nurses in various hospital wards completed a questionnaire survey. The inclusion criteria included at least one year of employment and nurses' agreement to participate and complete the survey. Nurses who experienced nonwork-related musculoskeletal injuries due to accidents or illnesses were excluded from the study. All nurses had a university education and $76.4 \%$ of them were female. The mean age of the participants was 35.2 years old $(S D=19.1)$ and the majority of them were married (79\%). The average length of tenure was 17.4 years $(S D=8.9)$.

The research project and questionnaire were reviewed and approved by the ethical committee at Semnan University of Medical Sciences. Prior to collecting data all participants were asked to sign a written informed consent. Nurses were assured about the confidentiality of their responses.

We applied an adapted Persian questionnaire based on the version of the standardized Nordic Musculoskeletal questionnaire to measure subjective nurses' musculoskeletal disorders. The validity of the questionnaire has been supported for samples in Iran (19). In the present study the reliability of each questionnaire was evaluated by measuring the internal consistency with Cronbach's alpha. The final research questionnaire consisted of demographics, job characteristics, musculoskeletal symptoms, physical work factors, psychosocial work factors, and organizational factors. We asked nurses to indicate whether they experienced pain or discomfort at upper back, lower back, neck or shoulder, wrist, hand, elbow, and arm during the last 1 year-period. Criteria for muscular com- plaints were severity, duration, and frequency of the symptoms. The perceived risk of musculoskeletal symptoms measured by a 5 -point scale from $1=$ very unlikely to $5=$ very likely. Test of instrument indicated substantial internal reliability (Cronbach's coefficient) of 0.81 .

Participants' body postures at work were measured with a modified work analysis tool (20). Nurses responded to 4 items including "lifting far from body", "bending work performance", "standing position", "keeping awkward working position" based on a 5 point Likert scale rating from "never not at all = 1" to "the highest extent $=5$ ", and finally total rating classified into 3 ranges as low posture risk, moderate, and high posture risk. The validity of the questionnaire has been assessed before (21). Body posture scale obtained a relative good reliability (0.73).

Nurses perceptions of their valued psychological workload variable imposed upon them by the work environment was evaluated in this study by using 5 items focusing on "working too much hours", "carrying out more than 1 job", "working under time pressure", "work very fast", and "work hard" (22). The validity of the occupational stress questionnaire was tested in employees with musculoskeletal disorders (23). The reliability of the psychological workload was 0.76 . The relevant scale scores were calculated by summing nurses rating on the 5 items. Each item has 5 fixed response options ranging from not at all to a very great degree.

Role related stressors were measured using items "incompatible demands from supervisors" as role conflict and "work- family conflict" as inter role conflict. Reliability for this variable was 0.73 . Job satisfaction was measured using 3 items: "satisfaction of nursing profession", "enjoys working for the institution", and "feeling towards work" (24). The previous study has tested the instrument validity (25). Reliability for job satisfaction was 0.70 .

Perceived fatigue was measured with 10 items altogether, referring to latent factors about lack of motivation, sleepiness, lack of energy, and physical exertion (26). The validity of the fatigue questionnaire was tested in the prior study (27). The reliability of fatigue was 0.81 .

Individual factors were period of employment and body mass index (BMI). The latter calculated as the weight divided by the square of the height and classified as underweight, overweight, and obesity (28).

Descriptive statistics were computed to measure frequency, percentage, mean, and standard deviation. Chisquare test was used to evaluate the association between musculoskeletal symptoms outcomes as depended variables and non-continuous work environment stressors as independent variables. We applied a bivariate analysis of an independent sample t-test to assess the relationship between continuous variables and musculoskeletal symp- 
toms. Logistic regression was used to measure the direct effects of individual variables including age, sex, and body mass index on dichotomous musculoskeletal complaints. To examine the extent that independent variables relate to dependent latent variables, paths of standardized regression coefficients were determined from independent work body posture, psychological workload, role related stressors, and individual factors to dependent fatigue and work related musculoskeletal disorders. Data analyses were conducted using SPSS 19 version.

\section{Results}

Table 1 shows the prevalence rate of musculoskeletal disorders in terms of demographics and independent demographic as well as individual factors. This study measured various variables including work body posture, psychological workload, role related stressors, individual variables, fatigue, and musculoskeletal disorders.

Nurses reported the highest rate of musculoskeletal complaints in the lower back followed by shoulders and the lowest rate in hands and wrists. Perceived musculoskeletal disorders in the lower back, hand-wrist, and shoulder increased statistically with age $(\mathrm{P}=0.05)$. Women were reported with higher shoulder pain than men $(P$ $=0.04)$. Musculoskeletal disorders were more prevalent among nurses with longer years of employment in the shoulder, arm-elbow, neck, and lower back $(\mathrm{P}=0.03)$. There was no significant difference in musculoskeletal disorders in all body parts between nurses with a normal and high body mass index.

Overall, 78\% of hospital nurses reported the experience of complaints in at least one part of the body. Table 2 indicates the prevalence of musculoskeletal symptoms in terms of risk factors at the work environment. The findings indicated that about two-third of the nurses experienced musculoskeletal symptoms at 2 or more body parts. We found that the musculoskeletal complaints in body parts were related to higher levels of work posture, fatigue, job satisfaction, role-related stressors, and psychological stressors. However, statistical significant associations were found between musculoskeletal outcomes and some independent variables (Table 2). Nurses with poor posture at work perceived a significant increase in lower back pain $(\mathrm{P}=0.01)$. Fatigue and role-related stressors had a statistical relationship with hand-wrist and neck complaints ( $P$ $=0.04)$. Lower back and shoulder pain were more common among nurses with higher psychological stressors ( $\mathrm{P}$ $=0.05)$.

We measured the effects of independent variables on dependent variables. The path coefficients of the model suggest that for each standard deviation increase in psychological factors and role conflict stressors, work related musculoskeletal disorders increased by 0.25 and 0.21 , respectively. This implies that psychological variables and role conflict stressors appear to have had a positive and moderate direct effect on musculoskeletal disorders among nurses. Moreover, psychological workload had a significant and relatively strong indirect effect of 0.46 on musculoskeletal disorders via mediating variable of fatigue stressor. Role related stressors had a significant but small indirect effect of 0.12 via fatigue variable on musculoskeletal symptoms. Overall, the more nurses' perceived psychological workload and role conflict stressors, the more they perceived musculoskeletal symptoms.

Body posture during work had a significant effect of 0.21 as well as a strong indirect effect via fatigue (0.50) on musculoskeletal disorders. Therefore the total association of body posture on the nurses' perception of musculoskeletal symptoms was strong (0.71). There was not a significant association of years of employment on musculoskeletal disorders; however, we found a significant and moderate indirect effect of 0.38 via fatigue on musculoskeletal disorders. Therefore the total effect of years of employment on the perception of musculoskeletal symptoms was moderate.

Meanwhile, psychological workload and role related stressors demonstrated statistically significant positive relationship to each other. Psychological stressors showed positive relationships with body posture at work, indicating that the greater psychological workload resulted in the greater work posture demands. The correlation between independent role conflict and work posture and individual factors were rather small, which indicated no significant associations.

\section{Discussion}

The aim of this study was to examine the prevalence of musculoskeletal disorders among a sample of hospital nurses and to evaluate the associations between stressors at work environment and musculoskeletal disorders.

Our findings revealed a high prevalence of musculoskeletal symptoms in hospital nurses. The prevalence of complaints in the lower back and neck were higher than the shoulder, arm-elbow, and hand-wrist. Adverse work posture, psychological work load, and role conflict as independent risk factors may be directly related to musculoskeletal disorders. We found strong support for hypothesized relationships of work posture on musculoskeletal complaints. An association between poor work posture and musculoskeletal symptoms has also been already reported (15). Possible explanation is that nursing tasks, er- 
Table 1. Prevalence Rate of Musculoskeletal Symptoms in Terms of Demographic and Individual Characteristics ${ }^{\mathrm{a}}$

\begin{tabular}{|c|c|c|c|c|c|c|}
\hline \multirow[t]{2}{*}{ Variables } & \multirow[t]{2}{*}{ No. } & \multicolumn{5}{|c|}{ Parts of the Body } \\
\hline & & Shoulder & Arms-elbow & Hand-wrist & Neck & Lower back \\
\hline \multicolumn{7}{|l|}{ Age } \\
\hline $20-30$ & 45 & $5(11.1)^{b}$ & $8(17.7)$ & $4(8.9)^{b}$ & $12(26.7)$ & $13(28.9)^{\mathrm{b}}$ \\
\hline $30-40$ & 56 & $21(37.5)$ & $18(32.1)$ & $12(21.4)$ & $20(35.8)$ & $25(44.6)$ \\
\hline$>40$ & 22 & $15(68.1)$ & $12(54.5)$ & $13(59.1)$ & $17(77.3)$ & $21(95.4)$ \\
\hline \multicolumn{7}{|l|}{ Sex } \\
\hline Woman & 94 & $29(30.8)^{b}$ & $26(27.6)$ & $14(14.9)$ & $35(37.2)$ & $36(38.3)$ \\
\hline Man & 29 & $12(41.4)$ & $12(41.4)$ & $15(51.7)$ & $14(48.3)$ & $23(79.3)$ \\
\hline \multicolumn{7}{|c|}{ Employment duration, y } \\
\hline$<10$ & 69 & $16(23.2)^{b}$ & $13(18.8)^{b}$ & $13(18.8)$ & $17(24.7)^{\mathrm{b}}$ & $26(37.7)^{\mathrm{b}}$ \\
\hline$>10$ & 54 & $25(46.3)$ & $25(46.3)$ & $16(29.6)$ & $32(59.3)$ & $33(61.1)$ \\
\hline \multicolumn{7}{|c|}{ Body mass index } \\
\hline Normal & 72 & $19(26.4)$ & $28(38.9)$ & $12(16.7)$ & $28(38.9)$ & $25(34.7)$ \\
\hline High & 51 & $22(43.1)$ & $10(19.6)$ & $17(33.3)$ & $21(41.2)$ & $34(66.7)$ \\
\hline Total & 123 & $41(33.3)$ & $38(31.3)$ & $29(23.4)$ & $49(39.5)$ & $59(48.3)$ \\
\hline
\end{tabular}

${ }^{\mathrm{a}}$ Values are expressed as No. (\%)

${ }^{\mathrm{b}} \mathrm{P}$ value $<0.05$ by chi-square test.

Table 2. Prevalence Rate of Musculoskeletal Symptoms by Work Environment Stressors

\begin{tabular}{|c|c|c|c|c|c|}
\hline \multirow[t]{2}{*}{ Variables } & \multicolumn{5}{|c|}{ Parts of the Body } \\
\hline & Shoulder & Arms-elbow & Hand-wrist & Neck & Lower back \\
\hline \multicolumn{6}{|c|}{ Work posture } \\
\hline Good & $13(10.6)$ & $11(8.9)$ & $9(7.8)$ & $13(10.3)^{\mathrm{b}}$ & $17(13.8)^{\mathrm{c}}$ \\
\hline Poor & $54(44.3)$ & $28(22.8)$ & $24(19.9)$ & $46(37.2)$ & $51(41.3)$ \\
\hline \multicolumn{6}{|l|}{ Fatigue } \\
\hline Low & $22(18.3)$ & $18(14.8)$ & $15(12.5)^{\mathrm{b}}$ & $21(17.1)^{\mathrm{b}}$ & $18(14.5)$ \\
\hline High & $28(22.6)$ & $29(23.8)$ & $18(14.4)$ & $32(26.5)$ & $20(15.9)$ \\
\hline \multicolumn{6}{|c|}{ Job satisfaction } \\
\hline Low & $11(9.3)$ & $9(7.3)$ & $8(6.3)$ & $13(10.3)$ & $26(21.5)$ \\
\hline High & $18(14.3)$ & $16(12.7)$ & $15(11.9)$ & $24(19.2)$ & $29(23.8)$ \\
\hline \multicolumn{6}{|c|}{ Role-related stressors } \\
\hline Low & $17(13.8)$ & $18(14.3)$ & $17(13.6)^{\mathrm{b}}$ & $22(18.2)^{b}$ & $20(15.9)$ \\
\hline High & $28(22.7)$ & $17(13.9)$ & $25(20.3)$ & $33(27.2)$ & $36(29.3)$ \\
\hline \multicolumn{6}{|c|}{ Psychological stressors } \\
\hline Low & $18(14.9)^{\mathrm{b}}$ & $14(11.2)$ & $13(10.5)$ & $22(17.8)$ & $32(25.8)^{b}$ \\
\hline High & $23(19.1)$ & $17(13.3)$ & $20(16.3)$ & $31(25.2)$ & $43(34.9)$ \\
\hline
\end{tabular}

${ }^{\mathrm{a}}$ Values are expressed as No. (\%)

${ }^{\mathrm{b}} \mathrm{P}$ value $<0.05$ by chi-square test between subgroups.

${ }^{\mathrm{c}} \mathrm{P}$ value $<0.01$ by chi-square test between subgroups.

gonomically requiring more reaching and uncomfortable movement and posture, may put nurses at higher risk of musculoskeletal symptoms and injury. Previous research findings, however, indicated that the effect of physical factors was greatest in the development of work related musculoskeletal disorders $(10,17)$.

This study confirms that psychological workloads due to working hours and time pressure are related to musculoskeletal complaints. These findings do confirm the results from previous studies that psychologically stressful work may increase the musculoskeletal symptoms in the neck shoulder and upper and lower back $(7,16)$. Role related stressors were related to musculoskeletal complaints. This means that the more nurses experience stress 
due to conflicts between work and family responsibility as well as incompatible demands from supervisors may have more probability to develop musculoskeletal disorders. These results are in agreement with previous literature suggesting that as a result of changing in the work structure and performance, role related stressors are believed to be highly frequent and problematic in a variety of occupations (29).

Our study suggests that fatigue not only had a significant association with musculoskeletal disorders but was also demonstrated to be a considerable mediator of work posture, psychological and role conflict with musculoskeletal complaints. This implies that a higher level of perceived fatigue stem from work posture, psychological workload, and role conflict are related to increased risk for musculoskeletal disorders. Therefore the direct and indirect relations indicate that these risk factors did not have a unique effect on musculoskeletal symptoms. An interpretation of the results is that exposure to high levels of psychological stressors and adverse work posture may increase the possibility of musculoskeletal symptoms with first causing fatigue. Previous research showed that $\mathrm{cu}-$ mulative fatigue may have a potential link with musculoskeletal symptoms through a reduced capacity for stress, which may decrease the threshold stress at which the muscle tissue fails (30). Furthermore, a study found that selfreported fatigue may result in a reduced position sense perception and by disturbing motor control may cause musculoskeletal disorders (31). In essence, perceived fatigue as a mediator variable may suggest justification of how occupational and environmental factors put forth an impact on health outcome. Potential mediating effect of perceived fatigue may provide evidence that inappropriate posture at work may be hazardous to musculoskeletal system to the level that it causes fatigue.

In the present study low job satisfaction has not been identified as an important risk factor for adverse musculoskeletal related outcomes as statistically there was no direct or indirect association. In general, previous researches examined job satisfaction as a risk factor reported different and contradictory results. A variety of studies have generally found support for the association of low job satisfaction with low back pain and neck pain $(8,19)$. By contrast, one previous study indicated no relation between job satisfaction and neck or shoulder symptoms (29). Furthermore, a review study demonstrated that evidence was not consistent across different researches and study designs (32). Different results may be due to the fact that there are different theories and approaches to define and measure overall job satisfaction.

\subsection{Conclusions}

The hospital nurses perceived a high prevalence of musculoskeletal disorders in various body parts. We found relationships between aspects of work environment stressors and musculoskeletal. The results highlight that a combination of awkward work posture, fatigue psychological, and role related stressors was associated to an increased risk of work related musculoskeletal symptoms. In addition, we concluded that fatigue to some extent acts as a mediator between the stressors and musculoskeletal symptoms as perceived by nurses. In view of preventive measures, our study suggests that following exposure to high level of physical and psychological stressors, perceived fatigue may be regarded as a warning sign that recovery is needed to prevent the individual from suffering musculoskeletal symptoms and injuries.

There may be limitations with the current research and with the data set and method used in the analyses. The data was collected through a cross-sectional design, which limited the analyses of data over a short period of time and therefore cannot bring any verification of causality. Longitudinal researches are recommended to examine the causation. Further, the subjects in this study were limited to hospital nurses affiliated to university in a single area of Semnan province. For future research longitudinal designs in the nursing context and extended groups of hospitals are recommended to take into account variation in working conditions.

\section{Acknowledgments}

This study was supported and funded by Semnan University of Medical Sciences. We kindly thank the nurses for their contributions to this research work.

\section{Footnote}

Financial Disclosure: Authors have no financial interests related to the material in the manuscript.

\section{References}

1. Azma K, Hosseini A, Safarian MH, Abedi M. Evaluation of the Relationship Between Musculoskeletal Discomforts and Occupational Stressors Among Nurses. N Am J Med Sci. 2015;7(7):322-7. doi: 10.4103/19472714.161250. [PubMed: 26258080].

2. Arsalani N, Fallahi-Khoshknab M, Josephson M, Lagerstrom M. Musculoskeletal disorders and working conditions among Iranian nursing personnel. Int J Occup Saf Ergon. 2014;20(4):671-80. doi: 10.1080/10803548.2014.11077073. [PubMed: 25513802]. 
3. Herin F, Paris C, Levant A, Vignaud MC, Sobaszek A, Soulat JM, et al. Links between nurses' organisational work environment and upper limb musculoskeletal symptoms: independently of effortreward imbalance! The ORSOSA study. Pain. 2011;152(9):2006-15. doi: 10.1016/j.pain.2011.04.018. [PubMed: 21570771]

4. Bao SS, Kapellusch JM, Merryweather AS, Thiese MS, Garg A, Hegmann KT, et al. Relationships between job organisational factors, biomechanical and psychosocial exposures. Ergonomics. 2016;59(2):179-94. doi: 10.1080/00140139.2015.1065347. [PubMed: 26102483].

5. Barzideh M, Choobineh AR, Tabatabaee HR. Job stress dimensions and their relationship to musculoskeletal disorders in Iranian nurses. Work. 2014;47(4):423-9. doi: 10.3233/WOR-121585. [PubMed: 23324727].

6. Lee H, Ahn H, Park CG, Kim SJ, Moon SH. Psychosocial Factors and Work-related Musculoskeletal Disorders among Southeastern Asian Female Workers Living in Korea. SafHealth Work. 2011;2(2):183-93. doi: 10.5491/SHAW.2011.2.2.183. [PubMed: 22953201].

7. Eatough EM, Way JD, Chang $\mathrm{CH}$. Understanding the link between psychosocial work stressors and work-related musculoskeletal complaints. Appl Ergon. 2012;43(3):554-63. doi: 10.1016/j.apergo.2011.08.009. [PubMed: 21944295].

8. Carneiro P, Martins J, Torres M. Musculoskeletal disorder risk assessment in home care nurses. Work. 2015;51(4):657-65. doi:10.3233/WOR152024. [PubMed: 26409938]

9. Kim MG, Kim KS, Ryoo JH, Yoo SW. Relationship between Occupational Stress and Work-related Musculoskeletal Disorders in Korean Male Firefighters. Ann Occup Environ Med. 2013;25(1):9. doi: 10.1186/20524374-25-9. [PubMed: 24472292].

10. Heiden B, Weigl M, Angerer P, Muller A. Association of age and physical job demands with musculoskeletal disorders in nurses. Appl Ergon. 2013;44(4):652-8. doi: 10.1016/j.apergo.2013.01.001. [PubMed: 23399023].

11. Kraatz S, Lang J, Kraus T, Munster E, Ochsmann E. The incremental effect of psychosocial workplace factors on the development of neck and shoulder disorders: a systematic review of longitudinal studies. Int Arch Occup Environ Health. 2013;86(4):375-95. doi: 10.1007/s00420013-0848-y. [PubMed: 23549669].

12. Lamy S, Descatha A, Sobaszek A, Caroly S, De Gaudemaris R, Lang T. Role of the work-unit environment in the development of new shoulder pain among hospital workers: a longitudinal analysis. Scand J Work Environ Health. 2014;40(4):400-10. doi: 10.5271/sjweh.3430. [PubMed: 24728032].

13. da Costa BR, Vieira ER. Risk factors for work-related musculoskeletal disorders: A systematic review of recent longitudinal studies. Am JInd Med. 2010;53(3):285-323. doi:10.1002/ajim.20750. [PubMed:19753591].

14. Lovgren M, Gustavsson P, Melin B, Rudman A. Neck/shoulder and back pain in new graduate nurses: A growth mixture modeling analysis. Int J Nurs Stud. 2014;51(4):625-39. doi: 10.1016/j.ijnurstu.2013.08.009. [PubMed: 24094609].

15. Maakip I, Keegel T, Oakman J. Workstyle and Musculoskeletal Discomfort (MSD): Exploring the Influence of Work Culture in Malaysia. J Occup Rehabil. 2015;25(4):696-706. doi: 10.1007/s10926-015-9577-2. [PubMed: 25808991].

16. Golabadi M, Attarchi M, Raeisi S, Namvar M. Effects of psychosocial strain on back symptoms in Tehran general hospital nursing personnel. Arh Hig Rada Toksikol. 2013;64(4):505-12. doi: 10.2478/10004-125464-2013-2366. [PubMed: 24384756].

17. Markkanen P, Quinn M, Galligan C, Sama S, Brouillette N, Okyere D. Characterizing the nature of home care work and occupational hazards: a developmental intervention study. Am J Ind Med. 2014;57(4):445-57. doi: 10.1002/ajim.22287. [PubMed: 24347541].
18. Ricco M, Cattani S, Gualerzi G, Signorelli C. Work with visual display units and musculoskeletal disorders: A cross-sectional study. Med Pr. 2016;67(6):707-19. doi: 10.13075/mp.5893.00471. [PubMed: 28005080].

19. Arsalani N, Fallahi-Khoshknab M, Ghaffari M, Josephson $M$ Lagerstrom M. Adaptation of questionnaire measuring working conditions and health problems among Iranian nursing personnel. Asian Nurs Res (Korean Soc Nurs Sci). 2011;5(3):177-82. doi: 10.1016/j.anr.2011.09.004. [PubMed: 25030367].

20. Park JH, Park JH. Association among Work-Related Musculoskeletal Disorders, Job Stress, and Job Attitude of Occupational Therapists. Occup Ther Health Care. 2017;31(1):34-43. doi 10.1080/07380577.2016.1270482. [PubMed: 28094592].

21. van Nassau F, Chau JY, Lakerveld J, Bauman AE, van der Ploeg HP. Validity and responsiveness of four measures of occupational sitting and standing. Int J Behav Nutr Phys Act. 2015;12:144. doi: 10.1186/s12966-015 0306-1. [PubMed: 26608219].

22. Pullopdissakul S, Ekpanyaskul C, Taptagaporn S, Bundhukul A, Thepchatri A. Upper extremities musculoskeletal disorders: prevalence and associated ergonomic factors in an electronic assembly factory. Int J Occup Med Environ Health. 2013;26(5):751-61. doi: 10.2478/s13382013-0150-y. [PubMed: 24264438].

23. Chen WQ, Wong TW, Yu TS. Reliability and validity of the Occupational Stress Scale for Chinese off-shore oil installation workers. Stress Health. 2001;17(3):175-83. doi:10.1002/smi.898.

24. Widanarko B, Legg S, Devereux J, Stevenson M. Interaction between physical and psychosocial work risk factors for low back symptoms and its consequences amongst Indonesian coal mining workers. Appl Ergon. 2015;46 PtA:158-67. doi:10.1016/j.apergo.2014.07.016. [PubMed 25151314].

25. Faraci P,Valenti G. [Measuring job satisfaction: development of a multidimensional scale]. G Ital Med Lav Ergon. 2016;38(1):30-41. [PubMed: 27311143].

26. Van Eerd D, Munhall C, Irvin E, Rempel D, Brewer S, van der Beek AJ, et al. Effectiveness of workplace interventions in the prevention of upper extremity musculoskeletal disorders and symptoms: an update of the evidence. Occup Environ Med. 2016;73(1):62-70. doi: 10.1136/oemed-2015-102992. [PubMed: 26552695].

27. Stone AA, Broderick JE, Junghaenel DU, Schneider S, Schwartz JE. PROMIS fatigue, pain intensity, pain interference, pain behavior, physical function, depression, anxiety, and anger scales demonstrate ecological validity. J Clin Epidemiol. 2016;74:194-206. doi 10.1016/j.jclinepi.2015.08.029. [PubMed: 26628334].

28. W. H. O. Expert Consultation. Appropriate body-mass index for Asian populations and its implications for policy and intervention strategies. Lancet. 2004;363(9403):157-63. doi:10.1016/S0140-6736(03)152683. [PubMed: 14726171]

29. Stoyneva ZB, Dermendjiev S, Dermendjiev T, Dobrev H. Work-Related Upper Limb Disorders: A Case Report. Open Access Maced J Med Sci. 2015;3(1):146-50. doi: 10.3889/oamjms.2015.033. [PubMed: 27275213].

30. Parhizi S, Steege LM, Pasupathy KS. Mining the relationships between psychosocial factors and fatigue dimensions among registered nurses. Int J Ind Ergon. 2013;43(1):82-90. doi: 10.1016/j.ergon.2012.11.010.

31. Nimbarte AD, Chowdhury SK, Cartwright ED. Empirical evaluation of neck muscle fatigue generated by healthcare related exertions. Safety Science. 2013;57:100-7. doi:10.1016/j.ssci.2013.01.019.

32. Shieh SH, Sung FC, Su CH, Tsai Y, Hsieh VC. Increased low back pain risk in nurses with high workload for patient care: A questionnaire survey. Taiwan J Obstet Gynecol. 2016;55(4):525-9. doi: 10.1016/j.tjog.2016.06.013. [PubMed: 27590376]. 